\title{
EDITORIAL
}

\section{Integridad científica: principio que inspira el prestigio}

Rubén A. ANANIAS

Editor-in-Chief

La sociedad del conocimiento se caracteriza por generar riqueza y bienestar, basado en que la $\mathrm{I}+\mathrm{D}+\mathrm{i}$ se ha puesto al servicio del desarrollo económico (Ananías 2014). En este nuevo contexto, las buenas prácticas científicas cobran una importante relevancia, lo que ha llevado a diversas organizaciones en el nivel mundial a declarar principios para una actividad científica responsable (Declaración de Singapur 2010, ESF 2011).

En la comunidad científica las actividades de investigación requieren evaluación, particularmente sensibles resultan los procesos de revisión por pares (peer review), que independiente del rigor científico se fundamentan en la confianza, por lo que no están exentos de problemas asociados a la parcialidad de juicios científicos, conflictos de interés no revelados, apropiación indebida de resultados de investigación, entre otros, que conducen a malas prácticas científicas.

La Declaración de Singapur (2010), establece que los investigadores al evaluar el trabajo de otros deben ser imparciales, rápidos, rigurosos y respetar la confidencialidad. En este sentido los investigadores sin las capacidades o el conocimiento apropiado al nivel del estado del arte, deben ser excusados para actuar como evaluadores de la calidad de un determinado paper o propuesta científica, ya que pierden objetividad al emitir sus juicios científicos. Esta incapacidad juega un rol crucial en la percepción negativa o positiva, ya que puede estar además condicionada por conflictos de interés no revelados y en ocasiones, resultar en desmedro del mérito científico de un original sometido a una revista científica o de una propuesta presentada a evaluación de proyectos concursables y competitivos. El mérito científico de un manuscrito o documento científico debe ser evaluado con integridad científica, de manera que un juicio científico discordante no sea considerado como la razón para emitir un dictamen desfavorable a la calidad científica del documento que se evalúa. 
Por otra parte, la creación de ambientes propicios para la investigación, es en mi sentido el arte de saber convivir en investigación, fortalece la buena reputación de sus miembros y el prestigio institucional. Impide la apropiación indebida de resultados debido a carencias de integridad y permite la formación de capital humano en un ambiente de buenas prácticas científicas. Recientemente algunos jóvenes investigadores en formación, resaltan la importancia de fomentar la integridad en los ambientes para la investigación científica, para favorecer su formación avanzada como investigadores (Sills 2014). La formación de capital humano es una responsabilidad con la que se debe saber convivir cuando se hace ciencia, se trata de una relación de orientación continua, eficiente y eficaz, transmitiendo que el éxito depende de logros y como éstos se obtienen en un determinado ámbito científico o profesional, que incluye la retroalimentación constructiva de conocimientos y habilidades, la puesta en contacto con redes de investigadores, la propiedad de los resultados, entre otros, sin abuso de poder y aprovechamiento indebido de resultados, favoreciendo un ambiente saludable para la investigación, se persigue responsablemente formar profesionales (Figura 1) o investigadores independientes, con conciencia de las buenas prácticas científicas.

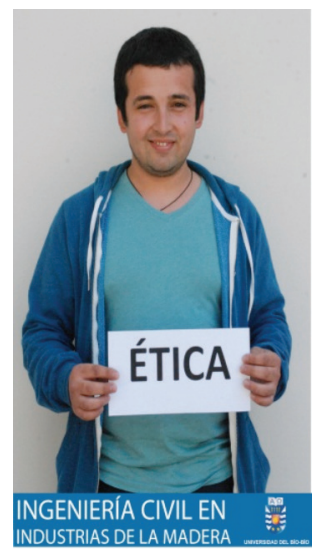

Figura 1: Ética profesional declarada en la formación profesional de Ingeniería Civil en Industrias de la Madera. (Fuente: Archivos de la Escuela de Ingeniería Civil en Industrias de la Madera, Facultad de Ingeniería, Universidad del Bío-Bío, Concepción, Chile).

Se cultiva $\mathrm{I}+\mathrm{D}+\mathrm{i}$ para contribuir a la sociedad del conocimiento en base a principios, siendo la integridad científica el valor que inspira el desarrollo de una cultura de buenas prácticas científicas, garantizando prestigio institucional y buena reputación a los miembros de la comunidad científica.

\section{Referencias}

Ananías, R.A. 2014. Sabiendo lo que hay que saber en Ciencias de la Madera: revalorizado en la sociedad del conocimiento. Maderas-Cienc Tecnol 16(3):273-274.

ESF. 2011. The European code of conduct for research integrity. European Science Foundation. $20 \mathrm{pp}$.

Sills, J. 2014. Science ethics: Young scientists speak. Science 345 (6192):24-27.

The Singapore Statement on Research Integrity. 2010. http://www.singaporestatement.org/. 